Vol. 11 (3): 557-568 (2021)

\title{
MEASURING THE COMPLEXITY OF URBAN FORM
}

\author{
Renilda Hyseni ${ }^{1 *}$, Florian Nepravishta ${ }^{1}$, Kristalba Asanbejlli ${ }^{1}$ \\ ${ }^{1 *}$ Polytechnic University of Tirana, Faculty of Architecture and Urbanism, Tirana, Albania; \\ *Correspondence Author Renilda Hyseni, e-mail: renildahyseni@gmial.com;
}

Received March 2021; Accepted April 2021; Published June 2021;

DOI: https://doi.org/10.31407/ijees11.327

\begin{abstract}
Complexity is one of the essential aspects of a sustainable city. Is well noting that urban designers talk about physical urban form and design projects in term of 'complexity' (e.g., Congress for the New Urbanism 2015). The field of urban complexity provides for the exploration and increased understanding of complex urban systems and their interaction through applying mathematical methodologies and modelling techniques, which allows for the potential to make cities more resilient, sustainable and efficient places to live in. Accordingly, this article focuses on analyzing the urban complexity through its components. The urban complexity helps us better understand the development of the cities and aim for a new way of urban intervention and development. In addition, in this article, we try to achieve a chronological path through theoretical and analytical studies while focusing on measuring the complexity of urban form, primarily through structural measures: fractal and network. This study aims to interpret the urban complexity by measuring the fractal dimension and density of a specific area in Tirana. So, the fractal dimension will give us quantitative information, making us understand the space that fills the constructions and qualitative data that makes us understand the compatibility of the traces left in the space by the built masses. However, the case study analysis show that fractal dimension and its measurement in time can serve for an even more accurate orientation of the whole urban process to reach a new way of urban planning and intervention, integrated it with other necessary elements of the urban form measurement.
\end{abstract}

Key words: urban complexity, structural complexity, fractal, network, measure. 